\title{
1 The efficiency of sieve-panels for bycatch separation in Nephrops trawls
}

2 Juan Santos ${ }^{\mathrm{a} * 1}$, Bent Herrmann ${ }^{\mathrm{b}}$ c*, Bernd Mieske ${ }^{\mathrm{a}}$, Ludvig A. Krag ${ }^{\mathrm{d}}$, Stefanie Haase ${ }^{\mathrm{e}}$, Daniel

3 Stepputtis $^{\mathrm{a}}$

4

5 a: Thünen Institute of Baltic Sea Fisheries, Alter Hafen Süd 2, 18069 Rostock, Germany

6 b: SINTEF Fisheries and Aquaculture, Fishing Gear Technology, Willemoesvej 2, 9850

7 Hirtshals, Denmark

8 c: Norwegian College of Fishery and Aquatic Science, University of Tromsø, 9037 Breivika,

9 Tromsø, Norway

10 d: DTU Aqua, National Institute of Aquatic Resources, North Sea Science Park, DK-9850

11 Hirtshals, Denmark

12 e: Institute for Hydrobiology and Fisheries Sciences, Grosse Elbstrasse 143, 22767 Hamburg,

13 Germany

14

15 *Equal authorship

$16{ }^{1}$ Corresponding author. Tel.: +49 (0) $381-8116122$

17 Email address: juan.santos@thuenen.de

\section{Abstract}

20 This study investigates the efficiency of a sieve-panel concept, intended to separate bycatch 
21 species from Nephrops (Norway lobster) in a trawl gear via mechanical and behavioral means.

22 Four different designs of varying panel mesh size or inclination were tested in experimental

23 fishing. For each design, we estimated the length-dependent sieving efficiency, defined as the

24 fraction of Nephrops or fish passing through the panel to the lower codend. The sieving 25 efficiency for Nephrops increased from $\sim 17 \%$ to $\sim 71 \%$ as mesh size increased, and it decreased 26 with increasing carapace length, but did so less as panel inclination and mesh size increased. The 27 sieving efficiency for roundfish was low, as intended, while the efficiency for flatfish decreased 28 with fish size. Although results are promising, the sieving efficiency for the largest, most 29 valuable Nephrops remained too low. Therefore, further improvements are necessary before the 30 concept is acceptable to the commercial fishing fleet.

31 Keywords: Nephrops, bycatch, trawl, sieve-panel, efficiency, Landing Obligation

\section{1. Introduction}

33 Nephrops (Nephrops norvegicus) directed fisheries are among the economically most important 34 fisheries in European waters (Ungfors et al., 2013). Although some creel fisheries target 35 Nephrops (Adey, 2007), 95\% of total European landings are taken by demersal trawlers (Briggs, 36 2010; Ungfors et al., 2013). Catching Nephrops efficiently with trawls requires using relatively 37 small mesh codends (Krag et al., 2008; Frandsen et al., 2010), which can lead to large bycatches 38 of small fish co-habiting the fishing grounds (Alverson et al., 1994; Catchpole and Revill, 2008;

39 Catchpole et al., 2007; Kelleher, 2005; Krag et al., 2008).

40 The problem of unwanted bycatch in Nephrops fisheries has been addressed mainly by 41 attempting to provide additional escapement possibilities for fish species before they enter the 42 codend (Catchpole and Revill, 2008). Although different in concept and purpose, all current 
43 devices are designed to reduce bycatch by selecting fish out of the catch. Probably the most used

44 bycatch reduction devices (BRDs) are the Swedish grid (Valentinsson and Ulmestrand, 2008) for 45 monospecific Nephrops fisheries, and square mesh panels (SMPs) for mixed fisheries 46 (Armstrong et al., 1998; Briggs, 1992). Although it has been demonstrated that using these BRDs 47 can significantly reduce bycatch rates, to date none of them have delivered an efficient size 48 selectivity for the target and bycatch species simultaneously. Depending on the population 49 structure fished, this can lead to a considerable number of bycaught small fish (Frandsen et al., 50 2009; Lövgren et al., 2016; Nikolic et al., 2015; Valentinsson and Ulmestrand, 2008), or losses of 51 marketable Nephrops (Catchpole et al., 2006; Frandsen et al., 2009).

52 Achieving an efficient size selection for both the target and bycatch species is an increasingly 53 important requirement in the wake of the Common Fisheries Policy (CFP) reform (EU 2013), 54 implemented in Nephrops fisheries since 2016. The reform adopted the Landing Obligation (LO) 55 for listed species, which forces fishers to land all catches of those species and count them against 56 their quota. Under such a scenario, a large bycatch of fish species with limited quota can alter the 57 fishing strategy or even force fishers to stop fishing completely, without exhausting the quota of 58 Nephrops. Improving species and size selectivity is required now more than ever to secure both 59 the biological and economical sustainability of Nephrops-directed fisheries.

60 This study presents an alternative concept for reducing fish bycatch in these fisheries. Our 61 concept shares similarities with the sieve nets used in shrimp trawl fisheries, such as the brown 62 shrimp fishery in the North Sea (Revill and Holst; 2004), and it is based on the assumptions that 63 Nephrops has limited swimming activity and tends to roll over the floor of the trawl body 64 (Briggs and Robertson, 1993; Main and Sangster, 1985), whereas fish tend to swim actively to 
65 stay clear of the surrounding net (Glass and Wardle, 1995). It consists of a 10-m-long square

66 mesh sieve-panel, mounted in the extension piece of the trawl with a continuous upward

67 inclination towards an upper and lower codend. The fore edge of the sieve-panel is attached to

68 the floor of the gear, ensuring that all Nephrops and fish will enter on the upper side of the panel

69 connected to the upper codend. Assuming that the behavioral differences between Nephrops and

70 the fish species listed above can be utilized, the panel will sieve Nephrops towards the lower

71 codend, and fish will be guided towards the upper codend. The mesh size used in the sieve- panel

72 and its inclination should be sufficiently large to sieve all sizes of Nephrops towards the lower

73 codend, without losing the ability to guide fish to the upper codend.

75 The aim of the study is to investigate and quantify the ability of different sieve-panel designs to

76 separate Nephrops from different roundfish and flatfish species during the catching process.

\section{2. Material and Methods}

78 2.1 Sieve-panel designs and test gear

79 The 10-m-long sieve-panel was mounted in the four-panel extension piece of the trawl (Figure

80 1). The fore edge of the sieve-panel was attached at the front of the extension's lower panel, and

81 the sides were connected to the lateral panels with a cutting rate of $6 \mathrm{~N} 2 \mathrm{~B}$. This construction

82 provides a monotonous upward-backward inclination of $\sim 2.5^{\circ}$, and splits the aft of the trawl into

83 two horizontal compartments, ending in the lower and upper codend (Figure 1).

84 Four different panel designs were tested during experimental fishing. All designs used square

85 mesh netting (Figure 1). Design 1 was made of knotless PA netting with $45.2 \mathrm{~mm}$ measured bar 
86 length and $2.5 \mathrm{~mm}$ nominal twine thickness. Design 2 used knotless PE netting with $60.9 \mathrm{~mm}$ bar

87 length and $5 \mathrm{~mm}$ twine thickness. Design 4 was constructed similarly to Designs 1 and 2 , but

88 used PE standard netting, with $94.3 \mathrm{~mm}$ mesh bar length and $3 \mathrm{~mm}$ twine thickness. Design 3

89 used the same sieve-panel as Design 2, but the monotonous inclination was altered by inserting

90 six floating lines, arranged in two groups of three and attached at two different positions on the

91 panel's lower side. The configuration was intended to create a hilly surface to increase the

92 inclination of the panel (Figure 1). For a sieve-panel to perform well, sieving efficiency should

93 be high for all sizes of Nephrops and low for all sizes of the bycatch species.

94 During experimental fishing, the sieve-panels were mounted one at a time for a group of hauls in

95 the same extension piece, which was $11.5 \mathrm{~m}$ long, made of PE single netting with $1.8 \mathrm{~mm}$ twine

96 thickness. The stretched mesh size obtained with the omega gauge (Fonteyne et al., 2007) was

$9747.9 \mathrm{~mm}$ (Figure 1). The codends were $6 \mathrm{~m}$ long and made of PA netting with $\sim 1.2 \mathrm{~mm}$ twine

98 thickness. The stretched mesh sizes of the codends were $48.4 \mathrm{~mm}$ and $49.6 \mathrm{~mm}$ for the upper and

99 lower codends, respectively. The codend mesh sizes applied were considered sufficiently small to

100 retain all Nephrops available in the targeted population. The extension piece and the double

101 codend system were connected to a demersal trawl model Spaeghugger, spread by two Thyborön

102 doors Type $2\left(1.78 \mathrm{~m}^{2}\right)$.

\subsection{Sea trials and data collection}

104 The four sieve-panels were tested September 12-24, 2015, on Danish Nephrops fishing grounds

105 in the Skagerrak (ICES Division IIIa), using the German research vessel "Solea" (42 m, 1780

$106 \mathrm{~kW}$ ). Catches obtained at haul level were sampled by species and for each codend separately. 
107 Catch weight was collected using electronic scales. The Nephrops carapace length (CL) was 108 measured to the nearest $0.5 \mathrm{~mm}$ using digital calipers. Total length (TL) was measured to nearest

$1090.5 \mathrm{~cm}$ for the fish bycatch species using electronic measuring boards. Subsampling was avoided

110 in most of the experimental hauls. When subsampling occurred, the subsampling factor was

111 calculated by dividing the subsampling weight by the total catch weight.

112 Underwater video recordings were collected during the experimental hauls to qualitatively assess

113 the shape of the sieve panel and how different species interacted with it. The cameras used were

114 GoPro model Hero 3+, mounted in deep-water housing, model GoBenthic2. The camera system 115 was supplemented with flood-beam artificial light (1400 lumens).

118 The sieving efficiency was quantified separately for each of the sieve-panels and each species as

119 described below.

120 With $n l c_{i l}$ as the number of individuals of length $l$ (CL or TL) caught in the lower codend during

121 Haul $i$, and $n u c_{i l}$ as the number of length $l$ caught in the upper codend, the proportion of the total 122 catch observed in the lower codend,

$123 \quad S_{i l}=\frac{n / c_{i l}}{n / c_{i l}+n u c_{i l}}$,

124 can be interpreted as the experimental sieving efficiency of the sieve-panel for individuals with 125 length $l$. $S_{i l}$ can only take values in the range $0.0-1.0$. Values of $S_{i l}$ close to 1.0 would mean that 
most individuals with length $l$ were sieved and finally retained in the lower codend. On the other

127 hand, $S_{i l}$ values close to 0.0 would mean low sieving efficiency, either because individuals of

128 length class $l$ were not physically able to pass through the meshes, or because the sieve-panel

129 guided them towards the upper codend.

130 The sieving efficiency might be influenced by the size selection of the square meshes and by

131 species behavior when interacting with the sieve-panel, which at the same time might be length

132 dependent. Therefore, length-dependent sieving efficiency is modelled by applying a highly

133 flexible function $S(l, q)$ :

$$
S(l, q)=\frac{\exp \left(f\left(l, q_{0}, \ldots, q_{j}\right)\right)}{1+\exp \left(f\left(l, q_{0}, \ldots, q_{j}\right)\right)}
$$

where $f$ is a polynomial of order $j$, with coefficients $q_{0}$ to $q_{j}$, which provide great flexibility to the functional form of the resulting sieve efficiency curve. The estimation of the values of the 138 parameters $\boldsymbol{q}=\left(q_{0}, \ldots, q_{j}\right)$, which make the observed experimental data averaged over hauls most

139 likely, was carried out by minimizing the negative log likelihood function for the binomial data:

$$
\log L_{\text {model }}=-\sum_{i} \sum_{i}\left\{n l c_{i l} \times \ln (S(I, q))+n u c_{i l} \times \ln (1.0-S(I, q))\right\}
$$

141 where the summations are for group of hauls $i$ with the specific sieve-panel design and length

142 classes $l$. In Equation 2, we considered $f$ as a polynomial up to the order 4 with parameters $q_{0}, q_{l}$,

$143 q_{2}, q_{3}$, and $q_{4}$. Leaving out one or more of the parameters $q_{0}-q_{4}$ led to 31 additional simpler 144 models that were also considered potential candidates for the sieve efficiency curves $S(l, \boldsymbol{q})$, and 
145 therefore they were also estimated using Equation 3. Selection of the best model for $S(l, \boldsymbol{q})$ among

146 the 32 competing models was based on a comparison of their respective Akaike information 147 criterion (AIC) values (Akaike, 1974). The model with the lowest AIC value was selected to 148 describe the experimental sieving efficiency.

149 The model's ability to describe the data was evaluated based on an inspection of the fit statistics, 150 i.e. the $p$-value and the model deviance vs. the degrees of freedom (df), following the procedures 151 described by Wileman et al. (1996). The $p$-value expresses the likelihood of obtaining a 152 discrepancy at least as large as between the fitted model and the observed experimental data by 153 coincidence. In case of poor fit statistics ( $p$-value $<0.05$; deviance $>>d f$ ), we examined if the 154 poor result was caused by structural problems when describing the experimental data using the 155 model, or if it was the result of overdispersion in the data (Wileman et al., 1996).

156 The $95 \%$ confidence intervals (CI) for the averaged sieve efficiency curve $S(l, q)$ were estimated 157 using a double bootstrap method with 1000 replications. This approach, which avoided 158 underestimating confidence limits when averaging over hauls, is identical with the one described 159 in Sistiaga et al. (2010). Traditionally, the CIs are estimated without accounting for potentially 160 increased uncertainty resulting from uncertainty in the selection of the model used to describe the 161 curve (Katsanevakis, 2006). Following the same method used by Krag et al. (2015), we 162 accounted for this additional uncertainty, by incorporating an automatic model selection based on 163 which of the 32 models produced the lowest AIC for each of the bootstrap iterations.

164 In addition to the assessment of the uncertainty of the individual averaged sieve curves, the 165 bootstrap CIs were used to compare Nephrops sieving efficiencies obtained for the different 166 sieve-panel designs. Such assessments were carried out as pairwise comparisons, and the 
differences within pairs were considered statistically significant only in the range of individual

168 lengths, where the compared CIs did not overlap. The analysis of sieve-panel efficiency was 169 carried out using the software tool SELNET (Herrmann et al., 2012).

\section{3.1. Description of experimental hauls and catches}

173 The experimental hauls were conducted in Danish fishing grounds within $57^{\circ}-58^{\circ} \mathrm{N}$ and $009-$

$174010^{\circ} \mathrm{E}$ (Figure S1 in supporting material) at fishing depths between 54 and $136 \mathrm{~m}$ (Table 1). Haul

175 duration ranged from 28 to 118 minutes. In all, 13, 10, 7, and 11 valid hauls were conducted 176 using Designs 1, 2, 3, and 4, respectively, a total of 41 experimental hauls. A total of 108 177 Nephrops were caught and measured with Design 1, a very small number compared with the 1782155,3669 , and 1627 individuals measured in Designs 2-4 (Table 1). Two roundfish and two 179 flatfish species were caught in sufficient numbers to warrant investigating the sieving 180 efficiencies on the fish species: American plaice (Hippoglossoides platessoides, 45363 fish 181 measured), blue whiting (Micromesistius poutassou, 13677 fish measured), cod (Gadus morhua, 1827804 fish measured), and witch flounder (Glyptocephalus cynoglossus, 5471 fish measured; 183 Table 1).

184 Of the Nephrops caught in the hauls with Design 1,17\% were collected in the lower codend, 185 increasing to $71 \%$ with Design 4 (Table 1). On the contrary, less than $10 \%$ of the cod, blue 186 whiting, and witch flounder caught were observed in the lower codend. Larger numbers of 187 American plaice were observed in the lower codend than the other fish species, increasing from 
189 A short haul in shallow and clear waters was conducted to collect video recordings showing the

190 shape and mechanical behavior of the extension piece with the sieve-panel mounted. video 191 recordings were collected during seven of the experimental hauls (Table 1), for a total of 561 192 minutes. Exploratory analysis of catch data indicated no clear influence of the camera system on 193 sieve panel performance; therefore, these hauls were used in the quantitative analysis.

\subsection{Assessment of the length-dependent sieving efficiency}

195 The sieving efficiency of each of the sieve-panel designs was successfully obtained using the 196 model described in Equation 2. $P$-values $>0.05$ were obtained in all cases, except for Nephrops in 197 Design 4, confirming the model's ability to describe the length-dependent sieving efficiency in 198 the experimental data (Table 2). The low $p$-value obtained for Nephrops Design 4 could indicate 199 the model's inability to describe the experimental data. However, inspection of the deviations 200 between the observed and modelled sieving efficiency did not reveal any clear pattern (Figure 2). 201 Therefore, we concluded that, in this case, the low $p$-value was caused by overdispersion in the 202 experimental data; therefore, we were confident in applying the model to describe the sieving 203 efficiency curve for Nephrops in Design 4 as well.

204 The model for Nephrops predicted a sieving curve with values of less than $40 \%$ for Design 1 , 205 decreasing in efficiency as carapace length increased (Figure 2). Larger percentages of Nephrops 206 catches were sieved using Designs 2-4, but many of the large individuals were still found in the 207 upper codend. The larger mesh size applied in Design 2 improved the sieving efficiency of 208 Design 1 significantly, estimated as being greater than $86 \%$ for CL $\leq 30 \mathrm{~mm}$, but decreasing 
209 drastically as CL increased. Increasing the inclination with the float lines applied in Design 3

210 reduced the monotonic decreasing trend in the sieving efficiency curve from Design 2, thereby

211 reducing the loss in sieving efficiency for the largest sizes. Finally, Design 4 clearly reduced the

212 negative trend observed in the previous designs, and the average sieving efficiency was not lower

213 than $45 \%$ throughout the experimental CL classes (Figure 2).

214 The increased mesh sizes from Design 1 to Design 2 resulted in an overall and significant 215 improvement in sieving efficiency, except for CL, which was larger than $260 \mathrm{~mm}$. Design 3's 216 sieving values were higher on average than Design 2's, but the improvement was not statistically 217 significant over the available CL range. Design 4 improved the sieving efficiency of Designs 2 218 and 3 on $\mathrm{CL} \sim 50 \mathrm{~mm}$ significantly and the efficiency of Design 2 on CL greater than $60 \mathrm{~mm}$ 219 (Figure 2).

220 For the bycatch species, less than $1 \%$ of cod (18 fish) were caught in the lower codend using 221 Design 1. A larger number of individuals (4.3\%) were sieved in Design 2, mostly in the range of 222 20-40 cm TL. Designs 3 and 4 increased the probability of small cod being sieved towards the 223 lower codend. Nevertheless, the averaged sieve curve from Design 4 remains below 20\% for 224 most of the TL classes available (Figure 3).

225 Negligible catches (3\%) of blue whiting were observed in the lower codend over the different 226 designs. Only the steeper inclination of the panel in Design 3 resulted in an increased sieving 227 efficiency for TL less than $30 \mathrm{~cm}$, however still less than $20 \%$ (Figure 3).

228 A considerable number of American plaice were observed in the lower codend and, as with 229 Nephrops, the sieving efficiency was strongly and negatively related to fish length. Similar 
curves were obtained for Designs 1-3. Sieving efficiency was increased over the whole length

231 range by Design 4 (Figure 4).

232 Sieve efficiency was lower and less dependent on fish length for witch flounder than for 233 American plaice. Consistent with results from the previous flatfish species, Design 4 raised the 234 sieving efficiency obtained by the other three designs considerably (Figure 4).

\subsection{Underwater video recordings}

237 The images collected confirmed that the shape of the sieve-panels were as intended. The sieve-

238 panel had a slight U-shape resulting from the drag of the water flow during towing (Figure S2 in

239 supporting material).

240 The sediments suspended in the water column made it difficult to collect quality video 241 sequences, and only a few of them revealed Nephrops interacting with the sieve-panels. Contrary 242 to expectations, most observations of Nephrops passing through the sieve-panel meshes occurred 243 through individuals' active behavior. One observation involved a first swimming phase, where 244 the individual contacted an open mesh tail-first (Figure S3, A.1 in supporting material). After 245 penetrating the mesh tail-first, the individual pushed the body downwards attempting to burrow 246 below the sieve-panel (Figure S3, A.2 in supporting material). At this stage, the individual stayed 247 with the claws upwards above the panel surface, and most of the body below it (Figure S3, A.3 in 248 supporting material), before pushing downwards again to pass the mesh completely and fall into 249 the lower compartment (Figure S3, A.4 in supporting material). On the contrary, other 250 individuals actively avoided being sieved by lying on the bar meshes (Figure S3, B in supporting 
material), holding the mesh twines with the chelipeds, both in the natural or reverse body orientation (Figure S3, C-E in supporting material), or simply by walking over the panel. In the

253 last case, some specimens were observed walking over the panel until they lost their balance and 254 finally drifted with the water flow towards the upper codend.

255 Most fish observed in the recordings followed the bottom-up inclination of the sieve-panel 256 without attempting to pass through the meshes. Few active passages of cod were observed during 257 the haul-back process, when cod attempted to swim downwards to balance the decrease in 258 hydrostatic pressure caused by the loss of depth.

\section{4. Discussion}

261 The progressive improvement in Nephrops sieving efficiency from Design 1 to Design 4 was 262 related to increments in the mesh size applied to the different panels. Although Design 2 clearly 263 improved on the performance of Design 1, the strong and negative length dependence in the 264 efficiency of this design makes it unfeasible for commercial adoption. Further increasing the 265 mesh size in Design 4 reduced the length dependence of the average sieve curve, but even with 266 such improvement, only $45 \%$ of the Nephrops larger than $55 \mathrm{~mm}$ CL were found in the lower 267 codend. Although Design 3 did not improve significantly on the efficiency of Design 2, the form 268 of the predicted curve indicates that increasing the inclination of the panel might benefit the 269 sieving efficiency..

270 Contrary to the original design assumptions, many sieving events observed in the underwater 271 video recordings occurred when individuals actively positioned the body in an optimal 
272 orientation towards the open meshes (Figure S3, A1-A4 in supporting material), whereas other

273 active interactions counteracted the sieving process (Figure S3, B-E in supporting material).

274 Based on the quantitative results and observation of the video recordings, we speculate that, in

275 addition to the passive process assumed in the design of the device, the sieving of Nephrops

276 might also be influenced by avoidance behavior, which could be stronger in large individuals.

277 Investigations conducted in tank aquariums demonstrated length-dependent avoidance behavior

278 only for male Nephrops (Newland et al., 1998). In particular, it was observed that larger males

279 reacted to tactile stimulus by producing fewer swimming bouts with more tail-flips per bout than

280 smaller individuals. Assuming that these findings can be extrapolated to the fishing grounds, we

281 speculate that avoidance behavior expected for large individuals could reduce the number of

282 times they contact the surface of the sieve panel compared to smaller individuals, reducing

283 therefore the sieving occurrences. Since the relationship between swimming performance and

284 individual length was found sex-dependent, Nephrops sex ratios in both the lower and upper

285 codend could be used as indicators to clarify if the behavioral observations in Newland et al.

286 (1998) could explain the length-dependent efficiency of the gear.

287 The sieving efficiency of cod was estimated at less than $20 \%$ for all reference lengths considered

288 (Table 3). In particular, the efficiency of $\mathrm{TL}=34 \mathrm{~cm}$ was $13 \%$, meaning that $87 \%$ were directed

289 towards the upper codend. It was assumed that using Nephrops-selective netting in the lower

290 codend would provide some escapement possibilities for small fish, thus lowering even further

291 the catch probability of undersized cod. The combination of a sieve-panel and selective codends

292 would therefore significantly improve the cod bycatch rates in trawls mounting the Swedish grid,

293 estimated at $\sim 30 \%$ for lengths $\sim 34 \mathrm{~cm}$ (Lövgren et al., 2016). 
294 The sieve-panel performed differently on roundfish and flatfish. The greater and strongly length295 dependent sieving efficiency observed for flatfish species is a consequence of their natural 296 behavior, tending to swim in close contact with the floor of the net (Ryer, 2008), and therefore 297 increasing the probability of being mechanically sieved to the lower codend.

298 Although the sieve-panel concept tested here is a promising tool for improving the exploitation 299 patterns in Nephrops fisheries, further improvements are necessary before the concept will be 300 acceptable to commercial fishing fleets. The results of the present study provide further 301 development opportunities of the concept in three different dimensions. First, a steeper 302 inclination of the sieve-panel could improve the sieving efficiency for Nephrops. We speculate 303 that this alteration in the original design might reduce the longitudinal transportation of 304 Nephrops over the panel, enhancing the possibility of being sieved through the meshes. On the 305 downside, a steeper angle might reduce the guiding effect, leading to larger fractions of fish 306 passing through the panel into the lower codend. Alternative mounting angles to be considered 307 for future designs should be between $30^{\circ}$ and $45^{\circ}$, a range used for other devices applied in 308 Nephrops fisheries such as the Swedish grid (Valentinsson and Ulmestrand, 2008), or separator 309 panels (Rihan and McDonnell, 2003). Increasing the mesh size used in Design 4 could facilitate 310 the sieving efficiency for Nephrops, whereas changing the mesh geometry to a rectangular shape 311 with the longitudinal opening oriented in the towing direction might reduce the sieving efficiency 312 for flatfish, because of the species' flat body shape. Finally, using thicker twine in the panel 313 construction might limit the Nephrops' ability to hold the twines and avoid being sieved.

314 Efficient separation of Nephrops and fish species might substantially reduce the unwanted 315 bycatch in European Nephrops-directed fisheries. By securing the Nephrops catch in a lower 
316 codend, fishers could mount an upper codend with a larger mesh size to catch larger fish. Under

317 fish quota exhaustion, catches of fish might be avoided by opening the upper codend during

318 towing. In addition to a better utilization of available quotas, other benefits can be expected by

319 dividing the species efficiently into separate codends: A proper separation would improve the

320 quality of marketable fish catches, as they are not subjected to damages in the skin and internal

321 tissues caused by the contact with the spiny appendixes of Nephrops (Karlsen et al., 2015;

322 Galbraith and Main, 1989). Exemptions to the Landing Obligation are contemplated in the

323 European legislation for species with scientific evidences of high survival rates after catch and

324 release. Most recent studies on Nephrops reported survival rates in the range of $\sim 20-60 \%$

325 (Méhault et al., 2016; Castro et al., 2003), therefore Nephrops could be one of these exemptions 326 under evidences of improved survival rates. Achieving "clean" Nephrops catches would 327 drastically reduce the overall catch volume in the lower codend, sorting time on deck and air 328 exposure, improving survival probability (Méhault et al., 2016; Harris and Andrews, 2005;

329 Castro et al., 2003).

330 Further investigations combining quantitative analysis of Nephrops behavioral patterns with 331 sieve-panels having different inclinations, mesh geometries, and twine thickness are planned. 332 Such future investigations could provide a better understanding of how mechanical and 333 behavioral size selection contributes to the observed sieving efficiency for Nephrops. This 334 information is required to create design guides for more efficient Nephrops sieve-panels to 335 achieve clean Nephrops catches in the lower codend, while ensuring minimal or no losses of 336 marketable individuals, so providing the industry with new technological alternatives to dealing 337 with the landing obligation enforced by the new European Fishing Policy. 


\section{References}

340 Adey, J.M. (2007). Aspects of the sustainability of creel fishing for Norway lobster, Nephrops

341 norvegicus (L.), on the west coast of Scotland. Doctoral dissertation, University of Glasgow.

343 Alverson, D.L., Freeberg, M.H., Murawaski, S.A., \& Pope, J.C. (1994). A global assessment of

344 fisheries bycatch and discards. FAO Fisheries Technical Paper No. 339, Rome, FAO.

346 Akaike, H. (1974). A new look at the statistical model identification. IEEE Trans. Auto. Control,

347 19, 716-723. 10.1109/tac.1974.110

349 Armstrong, M. J., Briggs, R. P., \& Rihan, D. (1998). A study of optimum positioning of square-

350 mesh escape panels in Irish Sea Nephrops trawls. Fisheries Research, 34, 179-189.

351 http://doi.org/10.1016/S0165-7836(97)00078-7

352 Briggs, R. P. (2010). A novel escape panel for trawl nets used in the Irish Sea Nephrops fishery.

353 Fisheries Research, 105, 118-124. http://doi.org/10.1016/j.fishres.2010.03.012

355 Briggs, R. P., \& Robertson, J. H. B. (1993). Square mesh panel studies in the Irish Sea Nephrops

356 fishery. ICES C.M. 1993/B20. (pp. 1-10). 
358 Briggs, R. (1992). An assessment of nets with a square mesh panel as a whiting conservation tool 359 in the Irish Sea Nephrops fishery. Fisheries Research, 13, 133-152. 360 https://doi.org/10.1016/0165-7836(92)90023-M

362 Castro, M., Araújo, A., Monteiro, P., Madeira, A. M., \& Silvert, W. (2003). The efficacy of 363 releasing caught Nephrops as a management measure. Fisheries Research, 65(1-3), 475-484.

365 Catchpole, T. L., \& Revill, A. S. (2008). Gear technology in Nephrops trawl fisheries. Reviews in 366 Fish Biology and Fisheries, 18, 17-31. doi:10.1007/s11160-007-9061-y.

368 Catchpole, T. L., Tidd, A. N., Kell, L. T., Revill, A. S., \& Dunlin, G. (2007). The potential for 369 new Nephrops trawl designs to positively effect North Sea stocks of cod, haddock and whiting. $370 \quad$ Fisheries Research, 86, 262-267.

372 Catchpole, T. L., Revill, A. S., \& Dunlin, G. (2006). An assessment of the Swedish grid and 373 square-mesh codend in the English (Farn Deeps) Nephrops fishery. Fisheries Research, 81, 118374125. 
EU 2013. Regulation No. 1380/2013 of The European Parliament And Of The Council of 11 $354 / 22$.

Fonteyne, R., Buglioni, G., Leonori, I., \& O’Neill, F. G. (2007). Review of mesh measurement methodologies. Fisheries Research, 85, 279-284. http://doi.org/10.1016/j.fishres.2007.02.012

Frandsen, R., Herrmann, B., \& Madsen, N. (2010). A simulation-based attempt to quantify the morphological component of size selectivity of Nephrops norvegicus in trawl codends. Fisheries Research, 101, 156-167. http://doi.org/10.1016/j.fishres.2009.09.017

387 Frandsen, R. P., Holst, R., \& Madsen, N. (2009). Evaluation of three levels of selective devices 388 relevant to management of the Danish Kattegat-Skagerrak Nephrops fishery. Fisheries Research, 97, 243-252. http://doi.org/10.1016/j.fishres.2009.02.010

391 Galbraith, R.D., \& Main, J. (1989). Separator panels for dual purpose fish/prawn trawls. Scottish 392 Fisheries Information Pamphlet Number 16.

394 Glass, C. W., \& Wardle, C. S. (1995). Studies on the use of visual stimuli to control fish escape 
395 from codends. II. The effect of a black tunnel on the reaction behaviour of fish in otter trawl 396 codends. Fisheries Research, 23, 165-174. https://doi.org/10.1016/0165-7836(94)00331-P

398 Harris, R. R., \& Andrews, M. B. (2005). Physiological changes in the Norway lobster Nephrops 399 norvegicus (L.) escaping and discarded from commercial trawls on the West Coast of Scotland: 400 II. Disturbances in haemolymph respiratory gases, tissue metabolites and swimming performance 401 after capture and during recovery. Journal of Experimental Marine Biology and Ecology, 320 402 (2), 195-210.

404 Herrmann, B., Sistiaga, M. B., Nielsen, K. N., Larsen, R. B. (2012). Understanding the size 405 selectivity of redfish (Sebastes spp.) in North Atlantic trawl codends. Journal of Northwest 406 Atlantic Fishery Science, 44, 1-13. doi:10.2960/J.v44.m680

408 Karlsen J.D., Krag L.A., Albertsen C.M. \& Frandsen R.P. (2015). From Fishing to Fish 409 Processing: Separation of Fish from Crustaceans in the Norway Lobster-Directed Multispecies 410 Trawl Fishery Improves Seafood Quality. PLoS ONE, 10 (11), e0140864. 411 http://doi:10.1371/journal.pone.0140864

413 Katsanevakis, S. (2006). Modelling fish growth: model selection, multi-model inference and 414 model selection uncertainty. Fisheries Research, 81, 229-235. 
415 http://doi.org/10.1016/j.fishres.2006.07.002

416

417 Kelleher, K. (2005). Discards in the world's marine fisheries: an update. FAO Fisheries Technical 418 Paper No. 470, Rome, FAO.

419

420 Krag, L. A., Herrmann, B., Karlsen, J. D., \& Mieske, B. (2015). Species selectivity in different

421 sized topless trawl designs: Does size matter?. Fisheries Research, 172, 243-249.

422 http://doi.org/10.1016/j.fishres.2015.07.010

423

424 Krag, L. A., Frandsen, R. P., \& Madsen, N. (2008). Evaluation of a simple means to reduce

425 discard in the Kattegat-Skagerrak Nephrops (Nephrops norvegicus) fishery: Commercial testing

426 of different codends and square-mesh panels. Fisheries Research, 91, 175-186.

427 http://doi.org/10.1016/j.fishres.2007.11.022

428

429 Lövgren, J., Herrmann, B., \& Feekings, J. (2016). Bell-shaped size selection in a bottom trawl: A 430 case study for Nephrops directed fishery with reduced catches of cod. Fisheries Research, 184, 431 26-35. http://doi.org/10.1016/j.fishres.2016.03.019

433 Main, J. \& Sangster, G. I. (1985). Trawling experiments with a two-level net to minimise the 434 undersized gadoid by-catch in a Nephrops fishery. Fisheries Research, 3, 131-145. 
437 Méhault, S., Morandeau, F., \& Kopp, D. (2016). Survival of discarded Nephrops norvegicus after 438 trawling in the Bay of Biscay. Fisheries Research, 183, 396-400.

440 Nikolic, N., Diméet, J., Fifas, S., Salaün, M., Ravard, D., Fauconnet, L., \& Rochet, M-J. (2015).

441 Efficacy of selective devices in reducing discards in the Nephrops trawl fishery in the Bay of

442 Biscay. ICES Journal of Marine Science, 72, 1869-1881. https://doi.org/10.1093/icesjms/fsv036

444 Revill, A. \& Holst, R. (2004). The selective properties of some sieve nets. Fisheries Research, 445 66, 171-183. http://doi.org/10.1016/S0165-7836(03)00198-X

447 Rihan, D.J. \& McDonnell, J. (2003). Protecting spawning cod in the Irish Sea through the use of 448 inclined separator panels in Nephrops trawls, ICES CM2003/Z:02

450 Ryer, C. H. (2008). A review of flatfish behavior relative to trawls. Fisheries Research, 90, 138451 146. http://doi.org/10.1016/j.fishres.2007.10.005

453 Sistiaga, M., Herrmann, B., Grimaldo, E., \& Larsen, R. B. (2010). Assessment of dual selection 
454 in grid based selectivity systems. Fisheries Research, 105, 187-199. 455 http://doi.org/10.1016/j.fishres.2010.05.006

457 Ungfors, A., Bell, E., Johnson, M. L., Cowing, D., Dobson, N. C., Bublitz, R., \& Sandell, J. 458 (2013). Nephrops fisheries in European waters. Advances in Marine Biology, the ecology and 459 biology of Nephrops norvegicus (pp. 247-306). UK: Elsevier.

461 Valentinsson, D. \& Ulmestrand, M. (2008). Species-selective Nephrops trawling: Swedish grid 462 experiments. Fisheries Research, 90, 109-117. http://doi.org/10.1016/j.fishres.2007.10.011

464 Wileman, D.A., Ferro, R.S.T., Fonteyne, R., \& Millar, R. B. (1996). Manual of methods of 465 measuring the selectivity of towed fishing gears. ICES Coop. Res. Rep. No. 215. 
467 Table 1. Summary of hauls conducted with the different Nephrops sieve-panel designs, including 468 the average towing duration (standard deviation in round brackets), and the number of individual 469 length-measurements obtained from each of the analyzed species and sampling compartments.

470 Subsampling rates are presented in square brackets for those cases where not all fish were 471 measured.

472

\begin{tabular}{|c|c|c|c|c|c|c|c|c|c|c|c|c|}
\hline \multirow[b]{2}{*}{ Design } & \multirow[b]{2}{*}{$\begin{array}{r}\text { Number } \\
\text { hauls }\end{array}$} & \multirow[b]{2}{*}{$\begin{array}{r}\text { Duration } \\
\text { (minutes) }\end{array}$} & \multicolumn{2}{|c|}{ Nephrops } & \multicolumn{2}{|c|}{ Cod } & \multicolumn{2}{|c|}{ Blue whiting } & \multicolumn{2}{|c|}{ American plaice } & \multicolumn{2}{|c|}{ Witch flounder } \\
\hline & & & $\begin{array}{r}\text { Lower } \\
\text { codend }\end{array}$ & $\begin{array}{r}\text { Upper } \\
\text { codend }\end{array}$ & $\begin{array}{l}\text { Lower } \\
\text { codend }\end{array}$ & $\begin{array}{r}\text { Upper } \\
\text { codend }\end{array}$ & $\begin{array}{l}\text { Lower } \\
\text { codend }\end{array}$ & $\begin{array}{r}\text { Upper } \\
\text { codend }\end{array}$ & $\begin{array}{l}\text { Lower } \\
\text { codend }\end{array}$ & $\begin{array}{r}\text { Upper } \\
\text { codend }\end{array}$ & $\begin{array}{l}\text { Lower } \\
\text { codend }\end{array}$ & $\begin{array}{r}\text { Upper } \\
\text { codend }\end{array}$ \\
\hline 1 & 13 & $54.5(31.0)$ & 19 & 89 & 18 & 2082 & 33 & 2530 & 1609 & $\begin{array}{r}6246 \\
{[0.973]}\end{array}$ & 0 & 1085 \\
\hline 2 & 10 & $100(29.0)$ & 1349 & 806 & 76 & 1693 & 24 & $\begin{array}{r}3863 \\
{[0.700]}\end{array}$ & 2561 & $\begin{array}{r}6799 \\
{[0.885]}\end{array}$ & 12 & 1034 \\
\hline 3 & 7 & $100.9(16.0)$ & 2537 & 1132 & 31 & $\begin{array}{r}563 \\
{[0.998]}\end{array}$ & 376 & 3606 & 2570 & 7110 & 14 & 898 \\
\hline 4 & 11 & 96.4 (13.9) & 1156 & 471 & 106 & 1135 & 18 & $\begin{array}{r}664 \\
{[0.730]}\end{array}$ & 5393 & $\begin{array}{r}5220 \\
{[0.856]}\end{array}$ & 134 & $\begin{array}{r}1209 \\
{[0.799]}\end{array}$ \\
\hline
\end{tabular}


473 Table 2. Sieving efficiency model statistics for the different species analyzed $(\mathrm{df}=$ model degrees of 474 freedom, $\mathrm{n}$ hauls $=$ number of hauls included in the analysis).

\begin{tabular}{|c|c|c|c|c|c|}
\hline Species & Parameter & Design 1 & Design 2 & Design 3 & Design 4 \\
\hline \multirow[t]{4}{*}{ Nephrops } & P-value & 0.90 & 0.86 & 0.15 & 0.04 \\
\hline & deviance & 36.79 & 72.07 & 98.68 & 101.29 \\
\hline & df & 49 & 86 & 85 & 78 \\
\hline & n hauls & 2 & 10 & 7 & 7 \\
\hline \multirow[t]{4}{*}{ Cod } & P-value & $>0.99$ & $>0.99$ & $>0.99$ & 0.99 \\
\hline & deviance & 56.90 & 50.54 & 34.57 & 64.78 \\
\hline & $\mathrm{df}$ & 111 & 108 & 86 & 93 \\
\hline & $\mathrm{n}$ hauls & 13 & 10 & 7 & 11 \\
\hline \multirow[t]{4}{*}{ Blue whiting } & P-value & 0.87 & 0.99 & 0.98 & 0.98 \\
\hline & deviance & 41.62 & 30.8 & 29.96 & 23.35 \\
\hline & $\mathrm{df}$ & 53 & 51 & 48 & 39 \\
\hline & $\mathrm{n}$ hauls & 7 & 9 & 7 & 11 \\
\hline \multirow[t]{4}{*}{ American plaice } & P-value & 0.13 & $>0.99$ & 0.97 & 0.65 \\
\hline & deviance & 54.76 & 25.14 & 30.48 & 42.81 \\
\hline & $\mathrm{df}$ & 44 & 50 & 47 & 47 \\
\hline & $\mathrm{n}$ hauls & 7 & 10 & 7 & 11 \\
\hline \multirow[t]{4}{*}{ Witch flounder } & P-Value & $>0.99$ & $>0.99$ & 0.95 & 0.64 \\
\hline & deviance & 0.00 & 23.52 & 35.41 & 46.89 \\
\hline & d.o.f & 47 & 51 & 51 & 51 \\
\hline & n hauls & 11 & 10 & 7 & 11 \\
\hline
\end{tabular}


475

476

477

478

\section{Figure captions:}

Figure 1. Top: Side view of the experimental gear with the general design of the sieve-panel (blue stippled line) mounted ahead of the double codend setup. For the sorting system to work efficiently, the following selection events have to take place consistently: (1) Assuming that Nephrops travels towards the codends by rolling and hitting the lower panel of the net, it is expected that they will be sorted by the sieve-panel to the lower codend (orange path); (2) the bottom-up inclination of the panel should guide fish upwards towards the upper codend (green path). Middle: Number of meshes of the different sieve-panel designs; additional floats (blue) were mounted in Design 3. Bottom: Netting used in the different designs and the measured mesh bar length of each (s.d. in parentheses). Nets were scanned using the same scale, allowing a direct comparison between meshes.

Figure 2. First and second rows show the sieving efficiency curves (solid lines), 95\% bootstrap CIs (dashed lines), and experimental sieving data (points) obtained for Nephrops by each sievepanel design (D1= Design $1, \ldots$, D4= Design 4). Total catches (light grey shading) and catches in lower codend (dark grey shading) are plotted in the background. Third and fourth rows show pairwise comparisons of the Nephrops sieving efficiency achieved by each of the designs. The grey bands represent the $\mathrm{CI}$ associated to each of the estimated sieving efficiency curves. The top-right to bottom-left diagonal can be used to assess the effect of increasing mesh size, and the opposite diagonal to compare the effect of uneven sieve-panel inclination.

Figure 3. Sieving efficiency curves (solid lines), bootstrap CIs (dashed lines), and experimental sieving data (points) obtained by each design (D1= Design $1, \ldots, \mathrm{D} 4=$ Design 4$)$ on cod (top rows) and blue whiting (bottom rows). Total catches (light grey shading) and catches in the lower codend (dark grey shading) are plotted in the background.

Figure 4. Sieving efficiency curves (solid lines), bootstrap CIs (dashed lines), and experimental sieving data (points) obtained by each design (D1= Design $1, \ldots, \mathrm{D} 4=$ Design 4$)$ on American plaice (top rows) and witch flounder (bottom rows). Total catches (light grey shading) and 
505 catches in the lower codend (dark grey shading) are plotted in the background.

506

507 Supporting material:

508

509 Figure S1. Map of the fishing area (Skagerrak; ICES Division IIIa), where the experimental sea

510 trials took place. The top-right panel shows the towing tracks.

511

512 Figure S2. Pictures taken in shallow waters from Design 1 before beginning experimental

513 fishing. Above: View of the panel in the middle section with the camera oriented backwards

514 towards the codends. Below: Insertion of the sieve-panel to the floor of the extension.

515

516 Figure S3. Left: Screenshots from underwater video recordings taken in haul 25 (Design 3),

517 showing Nephrops individuals actively passing through the sieve-panel. Right: Different

518 behavioral patterns observed for Nephrops on the panel. Arrows point to chelipeds hanging on to

519 the mesh twines. 
Figure 1

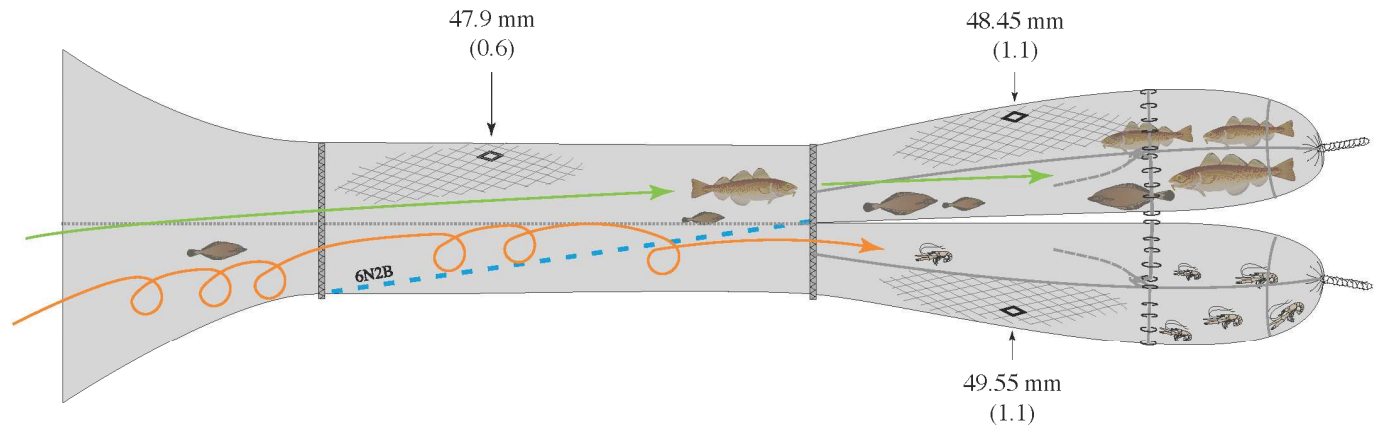

Design 1

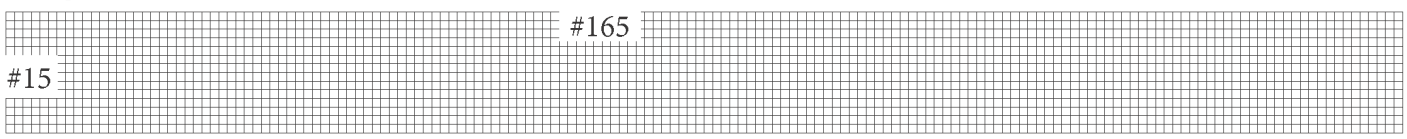

Design 2

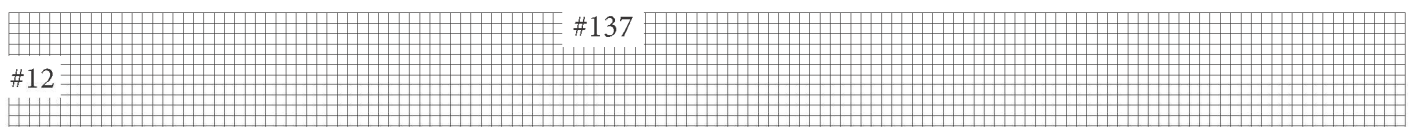

Design 3

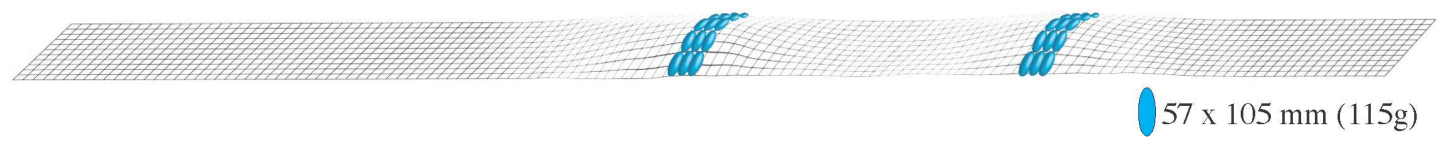

Design 4

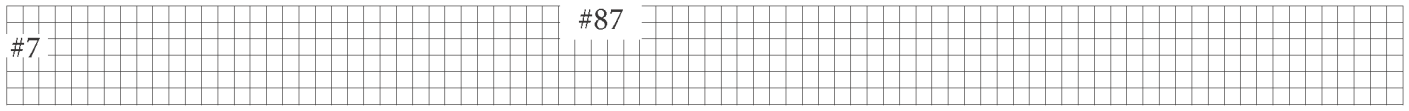

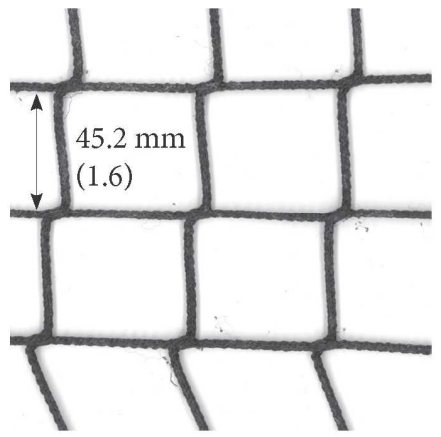

Design 1

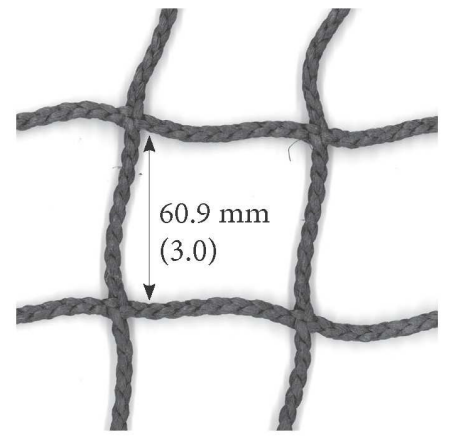

Design 2 and 3

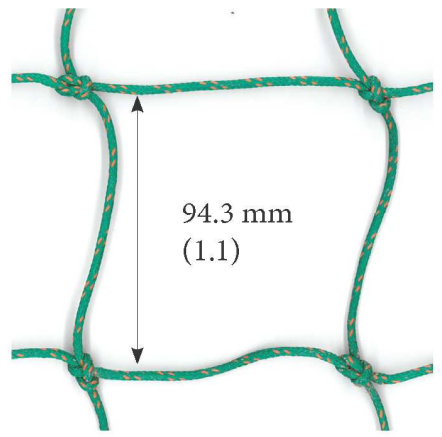

Design 4 
Figure 2

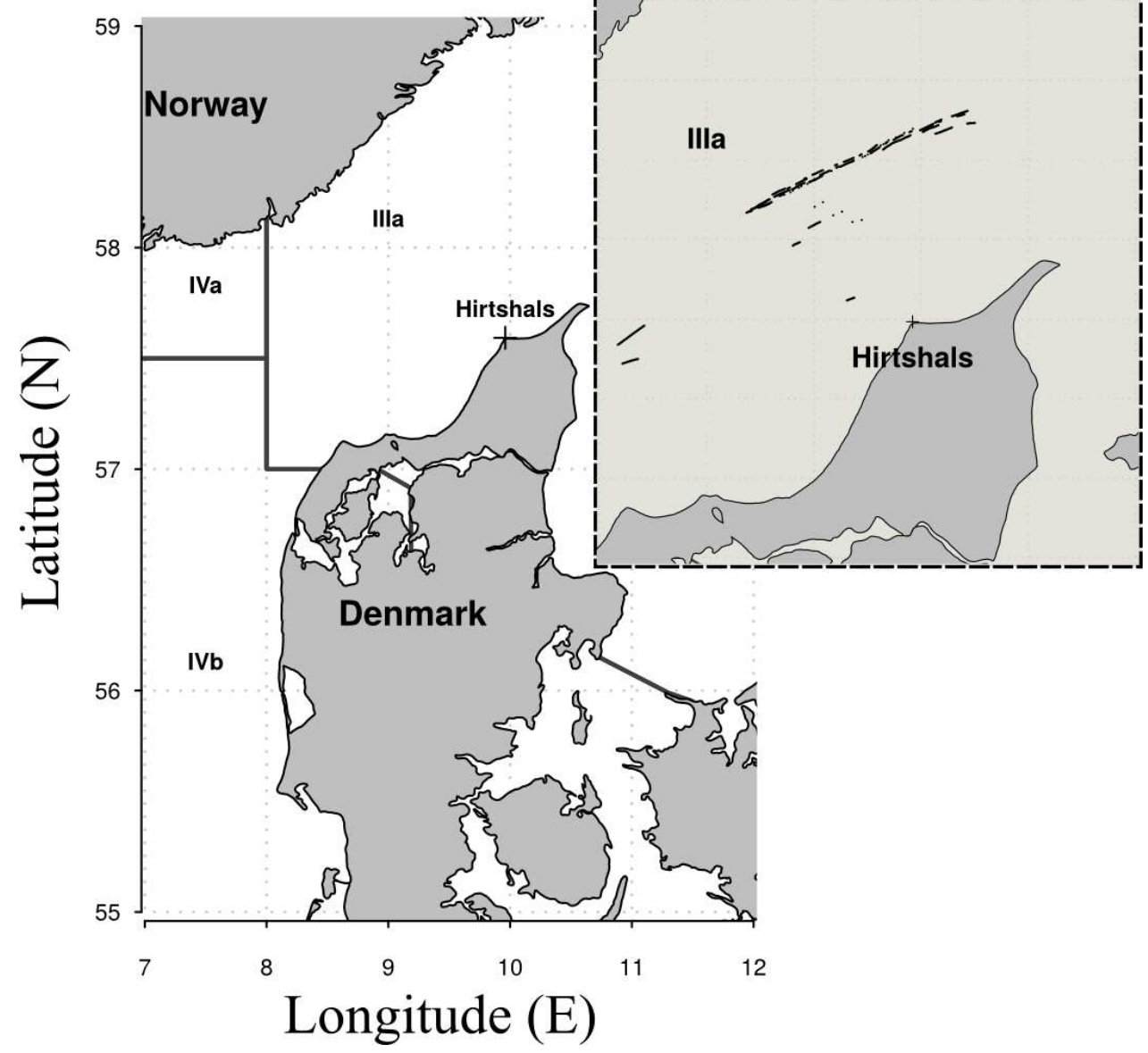


Figure 3
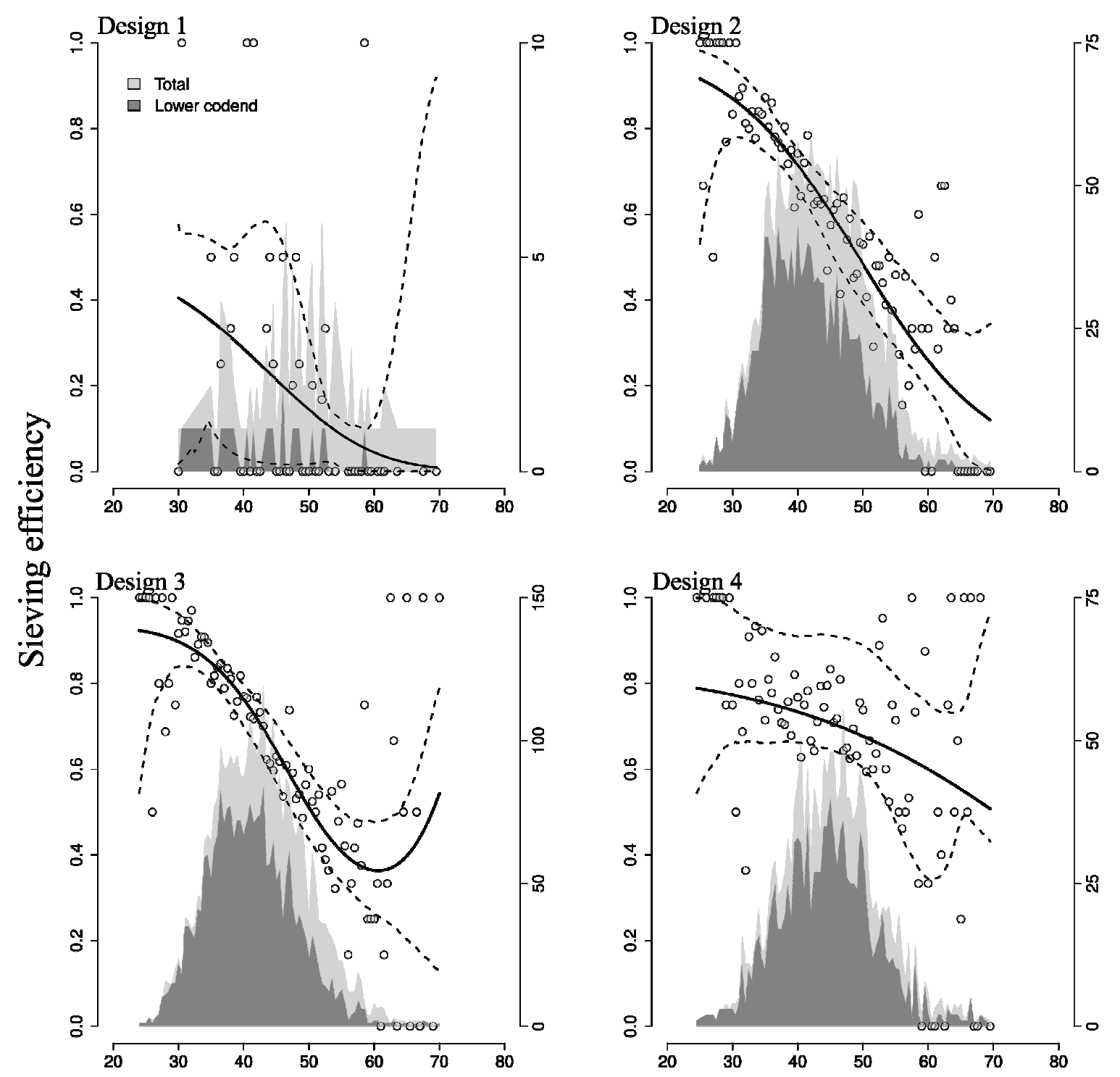

Carapace length (mm) 
Figure 4
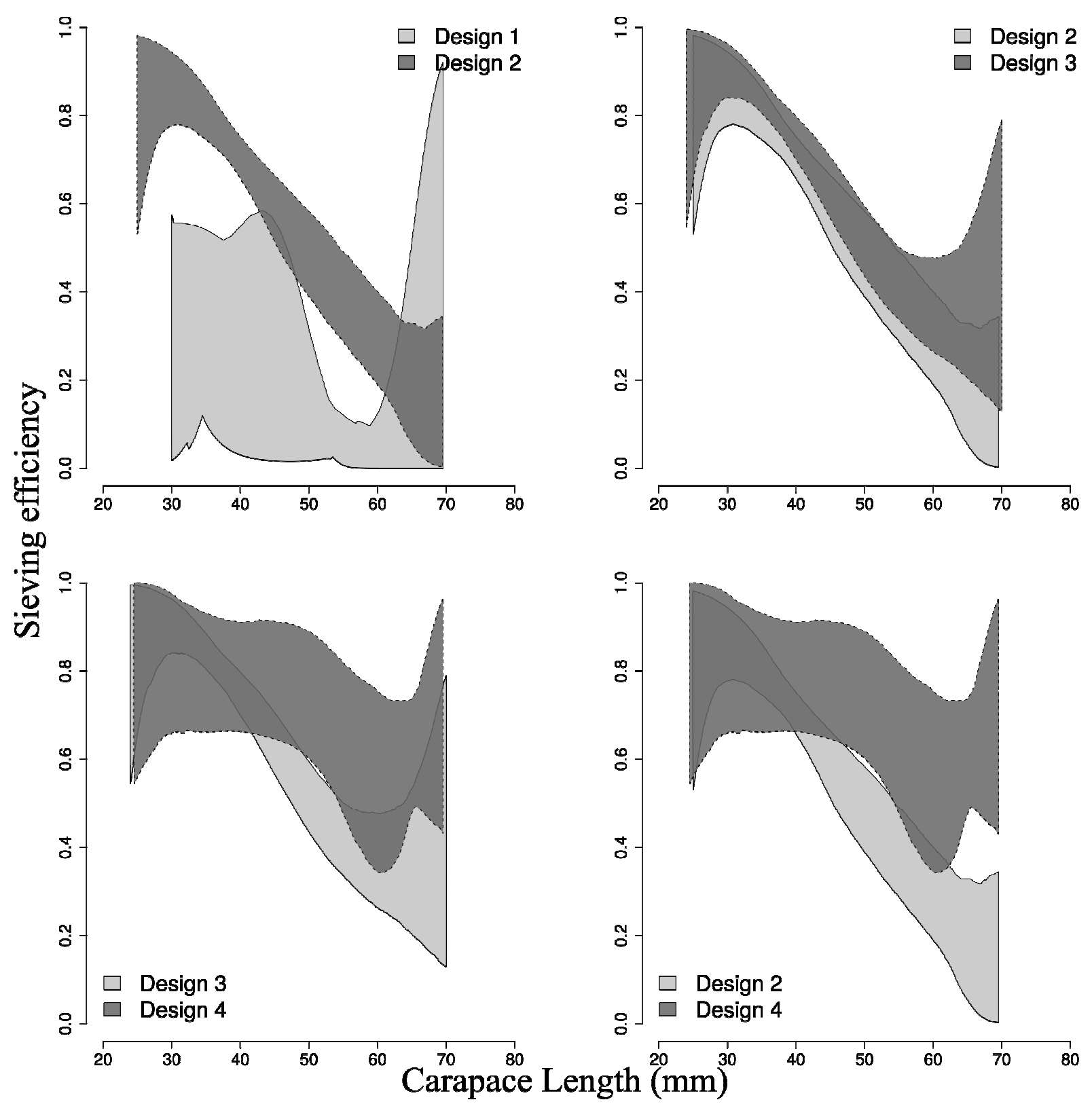
Figure 5
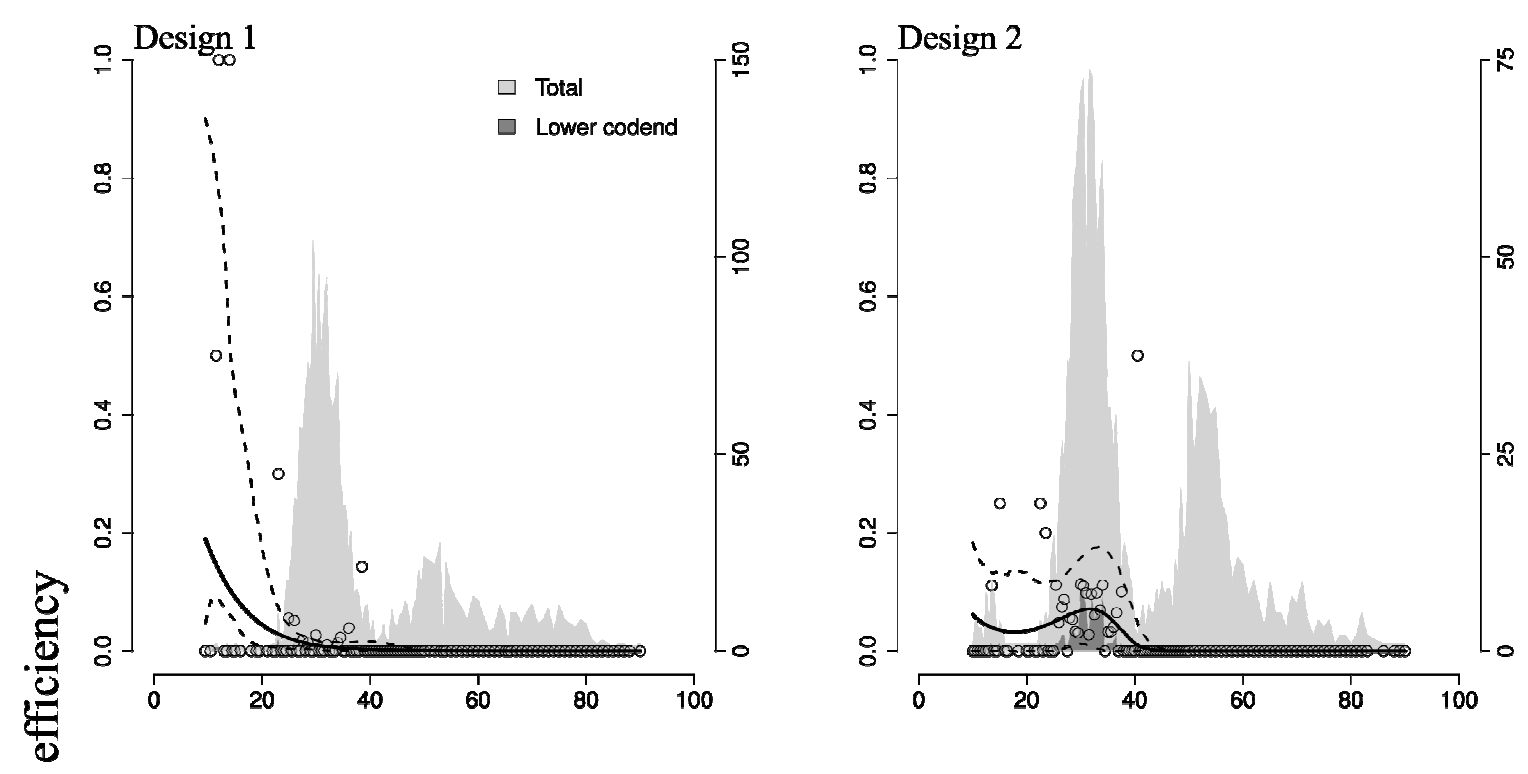

号
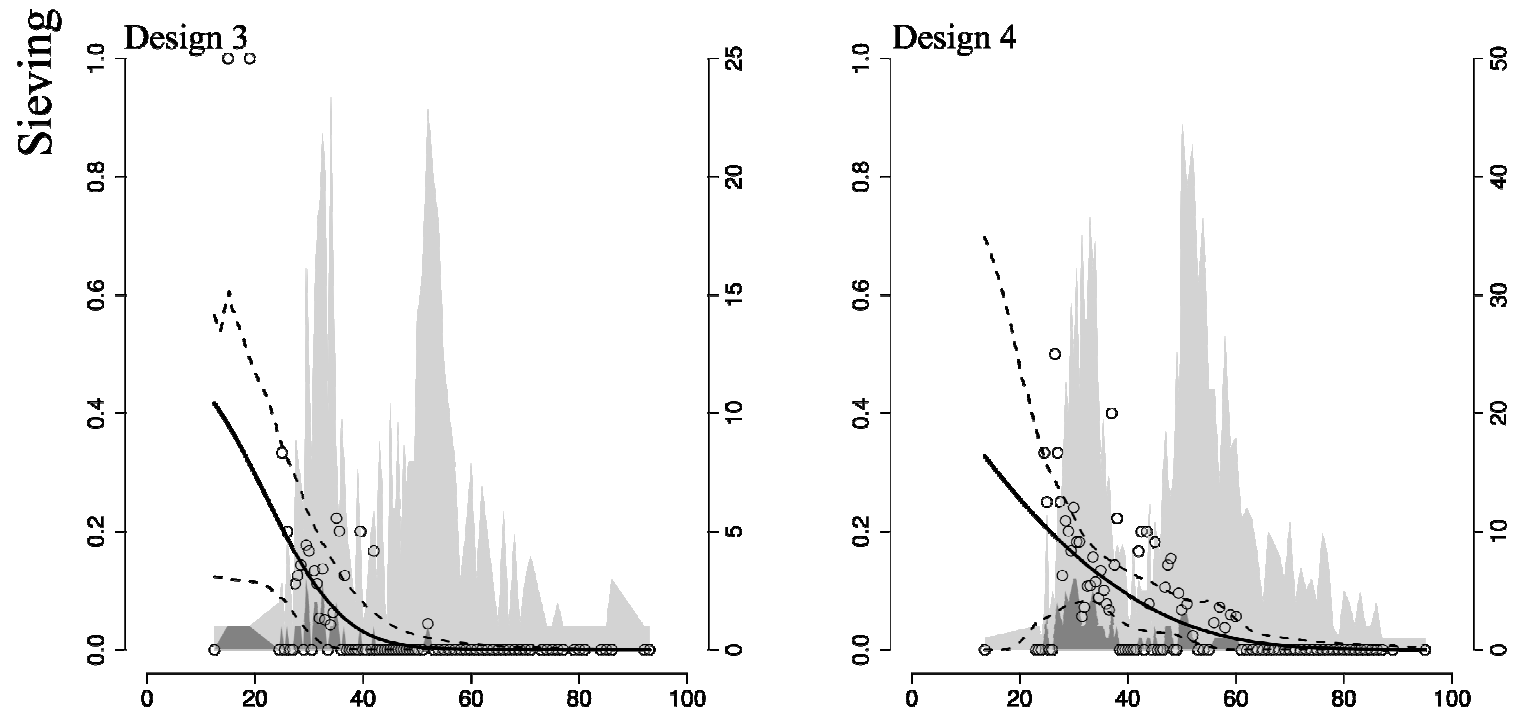

Length (cm) 
Figure 6
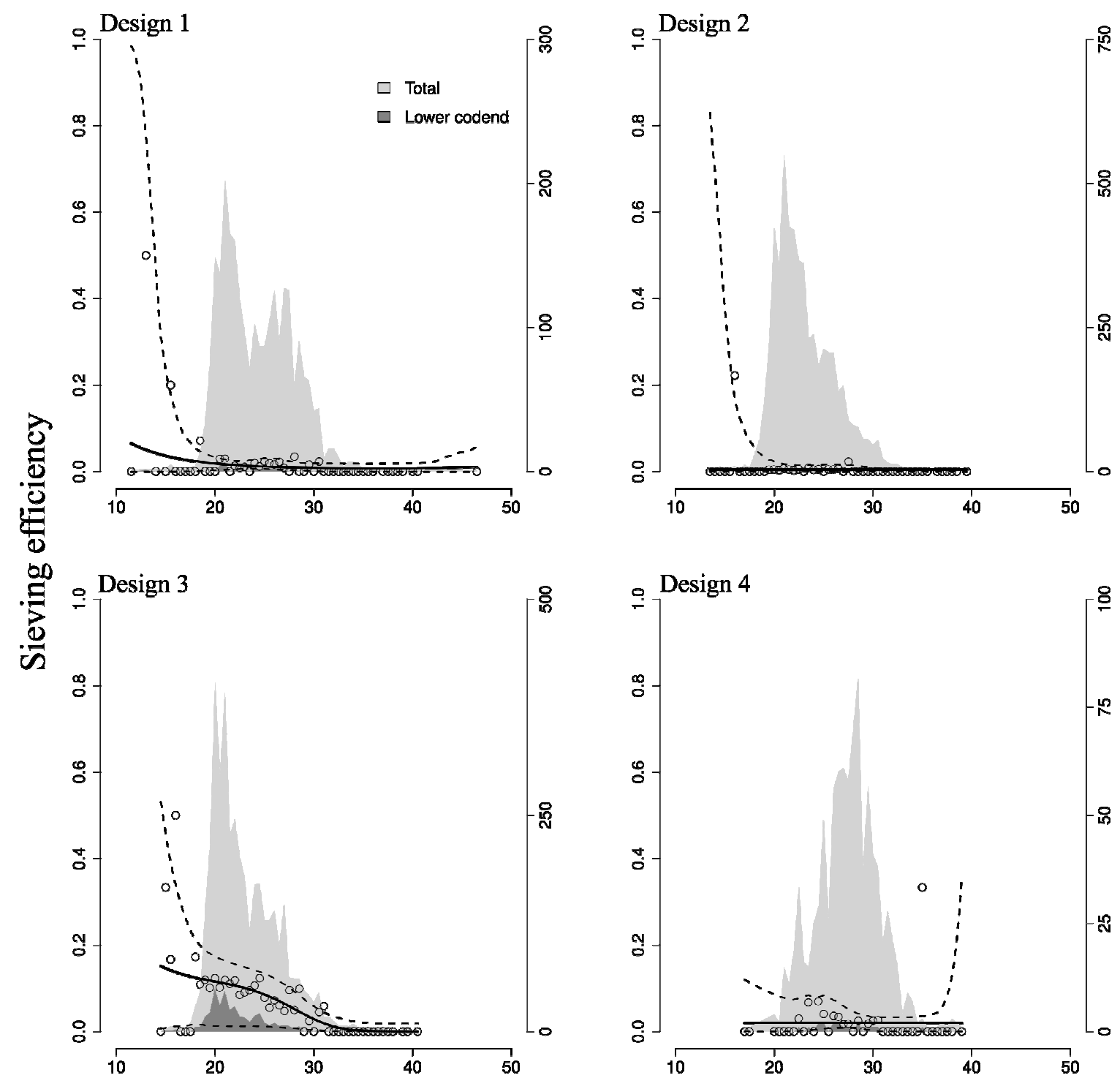

客

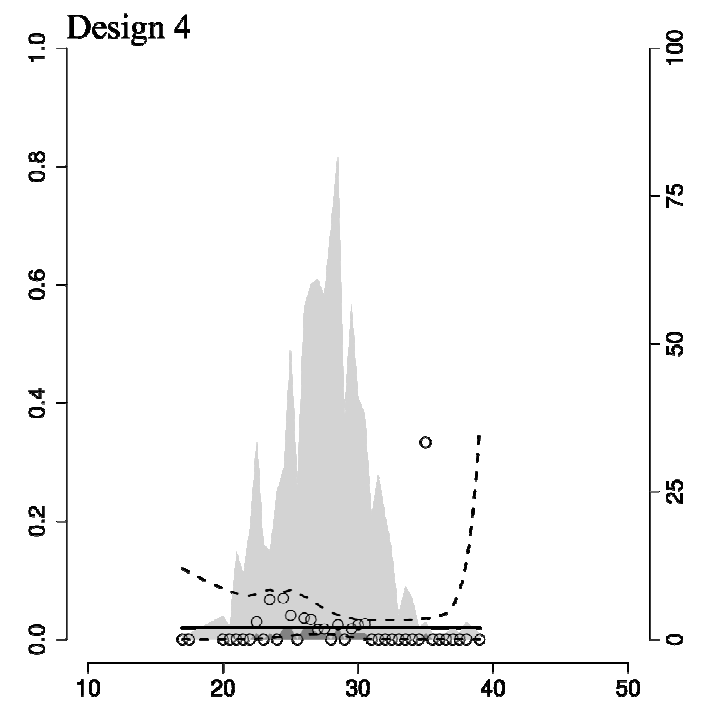

Length (cm) 
Figure 7
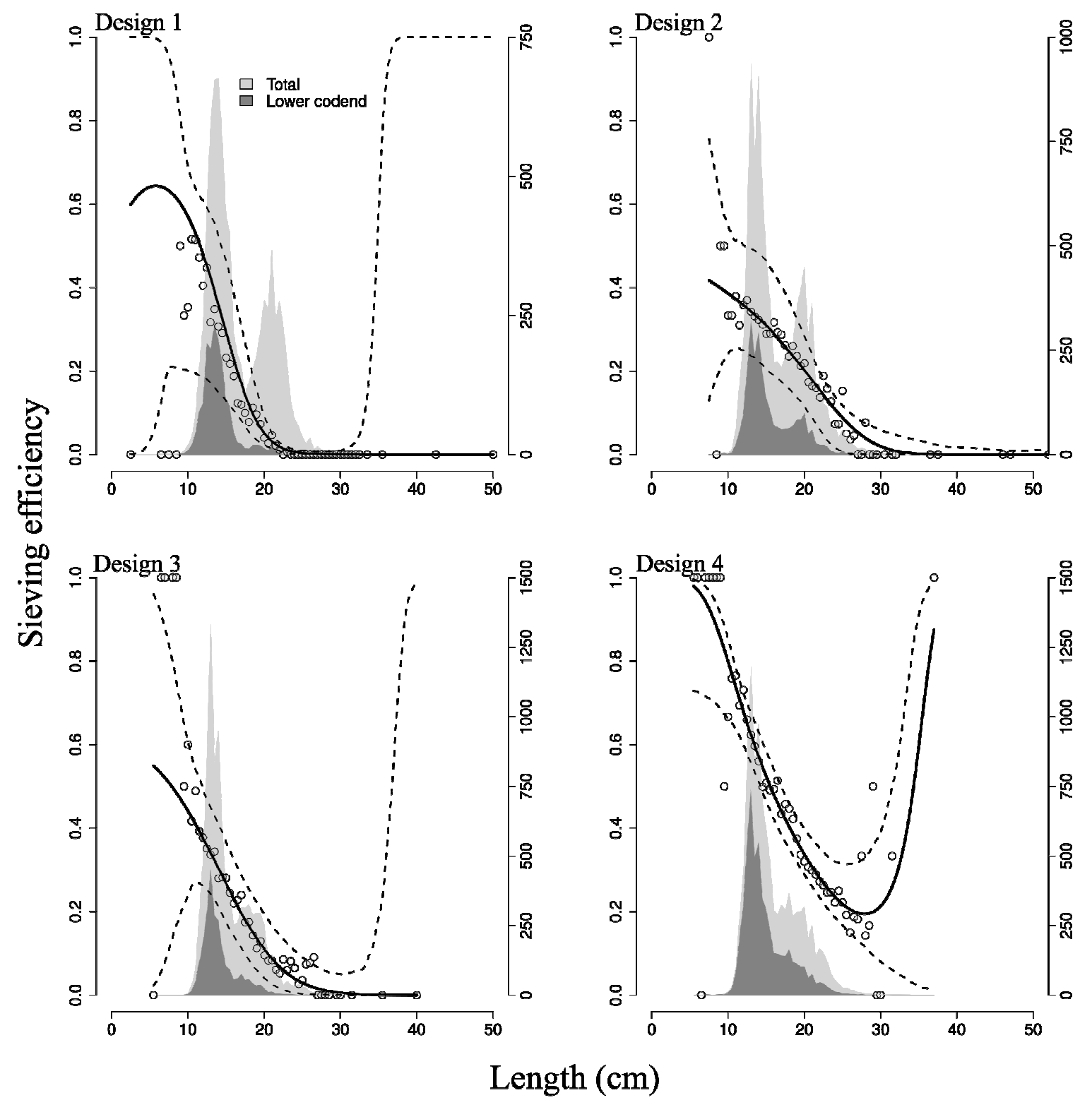

这

Length (cm) 
Figure 8
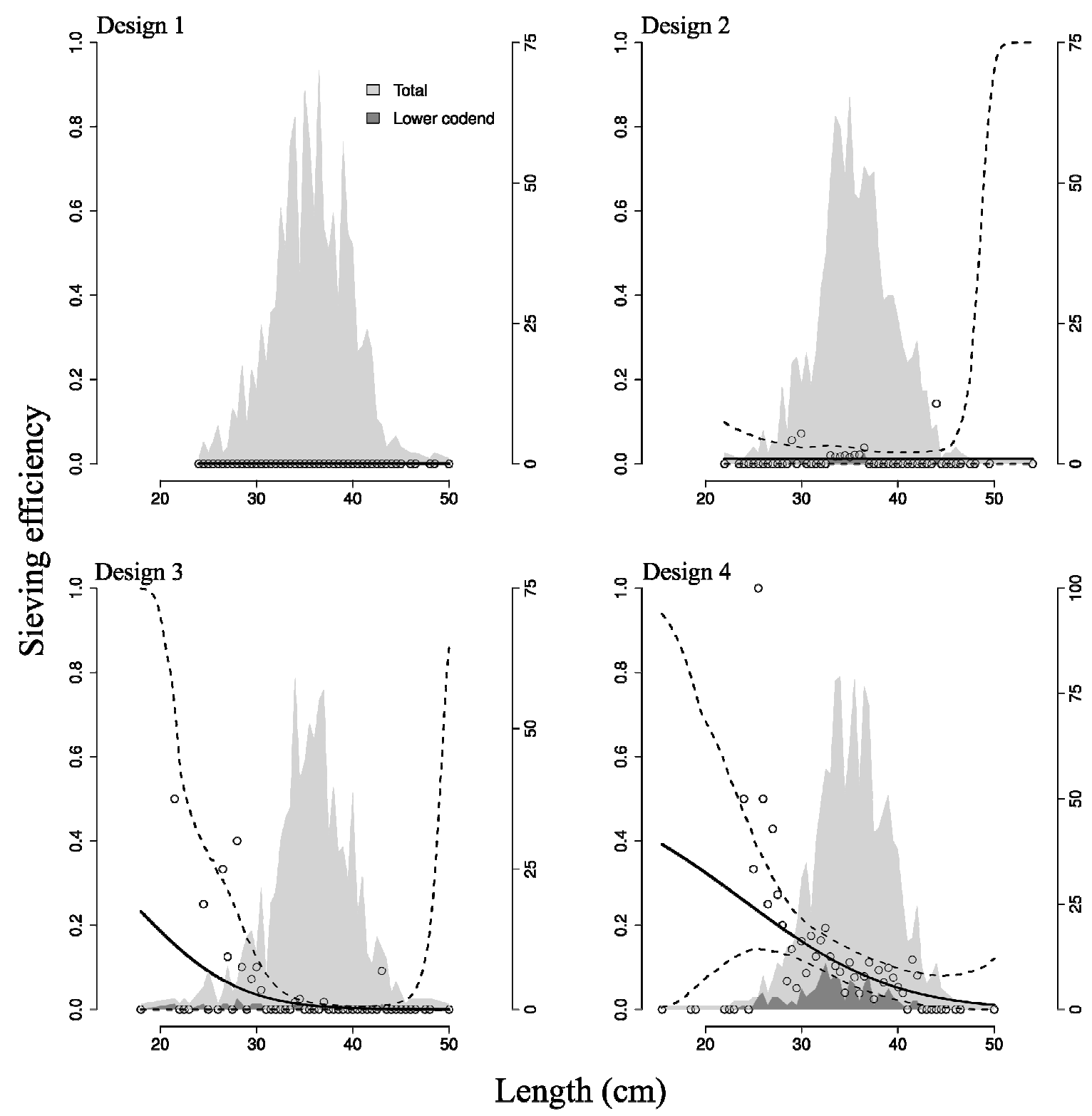

离

Length (cm) 
Figure 9
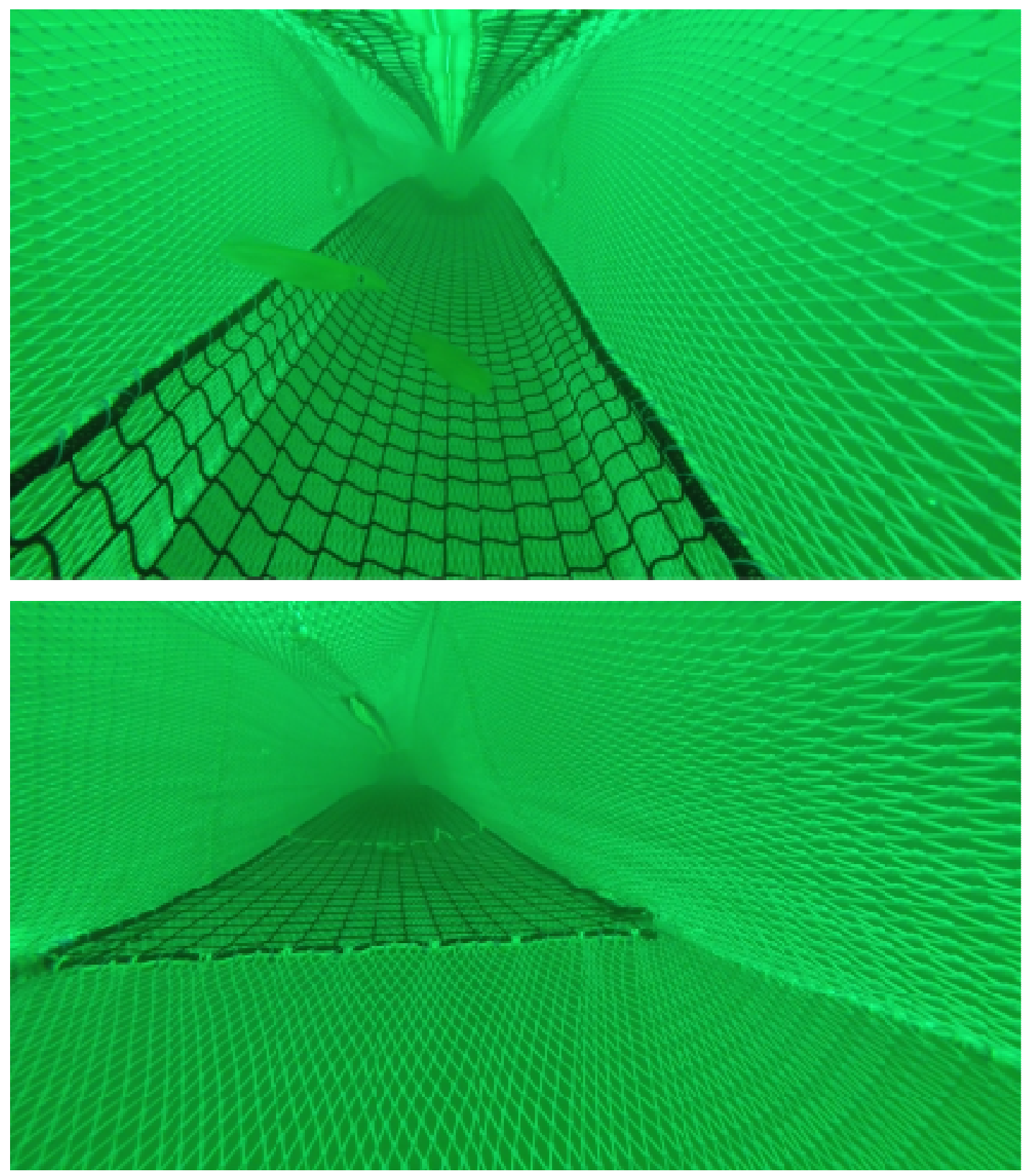
Figure 10

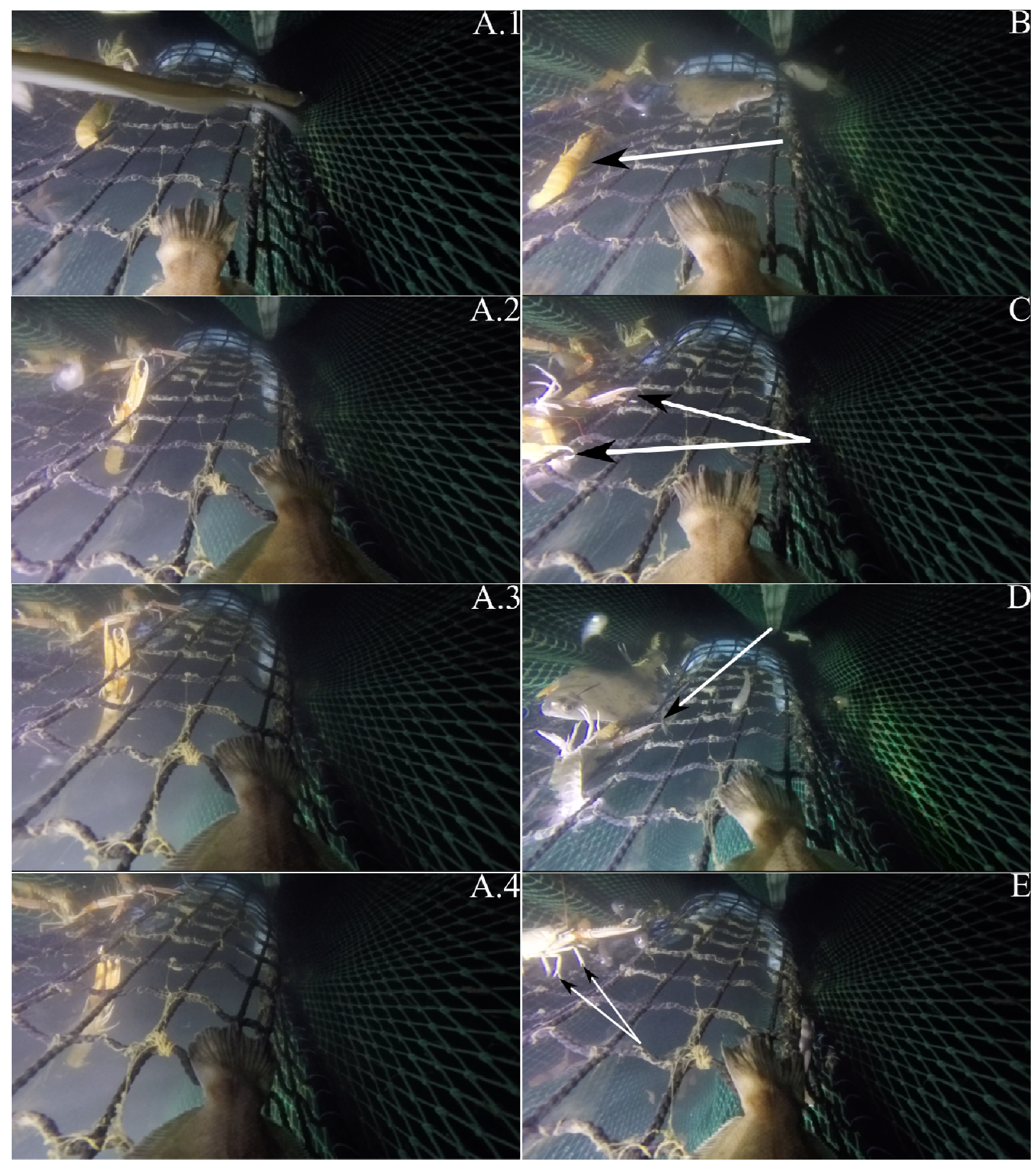

